\title{
Walk Your Life to Health-Motivating Young Adolescents to Engage in a Brisk Walking Program
}

\author{
W. W. A. Ma1, L. M. Y. Chung1, C. W. W. Fong1, D. Pendergast ${ }^{2 *}$ \\ ${ }^{1}$ Department of Health and Physical Education, The Hong Kong Institute of Education, Tai Po, Hong Kong, China \\ ${ }^{2}$ School of Education and Professional Studies, Griffith University, Brisbane, Australia \\ Email: "hosdeaneducation@griffith.edu.au
}

Received 13 July 2014; revised 30 August 2014; accepted 16 September 2014

Copyright (C) 2014 by authors and Scientific Research Publishing Inc.

This work is licensed under the Creative Commons Attribution International License (CC BY). http://creativecommons.org/licenses/by/4.0/

cC) (†) Open Access

\begin{abstract}
Increasing numbers of overweight and obese children resulting from sedentary and abundant lifestyles are a health concern in Hong Kong and other affluent communities around the globe. The importance of physical activity is well documented for health and wellbeing, with sedentary behavior emerging as an independent risk factor for chronic diseases and mortality. In this study, Pender's Health-Promotion Model informed the development of an intervention program aimed to engage junior high school students in increased physical activity, specifically brisk-walking. The model set out to motivate participants to engage in behaviors to enhance their health across the life span, including developing self-efficacy with regard to brisk walking. The intervention featured four stages. First, participants were provided with information about the benefits and in stage two were trained in the technique of brisk walking. Next they engaged in the brisk walking program and in stage four were encouraged to serve as health ambassadors by introducing brisk walking and its associated benefits to others, thereby exercising peer influence to diffuse the practice of brisk walking more widely among members of the community. Motivational strategies were used as incentives in the program, including the involvement of a popular singing band to award certificates at the completion of the program. This 7-week intervention program including a 4-week brisk walking component was conducted in a high school context with 71 participants. Data were collected to enable paired-sample t-tests to be conducted to statistically analyze the data at pre- and post-intervention. Findings indicate significant differences among the mean Body Mass Index (BMI), Waist-to-Hip Ratio (WHR), knowledge and attitudes of the participants at preand post-intervention. These findings suggest that the intervention was effective as a strategy to reduce sedentary behavior with the concomitant effect of positive shifts in measurable indicators and attitudes.
\end{abstract}

\footnotetext{
${ }^{*}$ Corresponding author.
} 


\section{Keywords}

\section{Health Education, Overweight Intervention, Brisk Walking, Social Cognitive Theory}

\section{Introduction}

In recent years, being overweight or obese has been recognized as a major health concern and more latterly as an intractable problem worldwide [1]. With a substantial increase in affluence and living standards, many young children in Hong Kong have access to diets featuring higher energy intake than expenditure. Along with this abundance, the shift towards a more sedentary lifestyle adds the impact of the over consumption of energy nutrients, with sedentary behavior emerging as an independent risk factor for chronic diseases and mortality [2]. Hence, a growing number of children and young adolescents exhibit weight-related health problems including physical, intellectual and social aspects and potentially increase the risk of reduced life expectancy, especially if they remain overweight from their adolescence to adulthood [3].

Though genetic predisposition may be a contributing factor, a range of potentially compounding factors including: the lack of physical exercise; unhealthy eating habits; unbalanced diet; overloaded school curricular activities; sedentary behaviors such as prolonged internet surfing and television viewing; insufficient parental knowledge of health; or a combination of these factors may contribute to this serious health problem [4]-[6].

A recent meta-analysis of sedentary behavior and cancer in 43 studies involving 68,938 people provides strong epidemiological evidence that prolonged sitting increases the risk of certain types of cancers [2]. This is gravely concerning as there is no dispute that in recent years increased television viewing and computer use along with less physically demanding lifestyles have led more people to be sedentary in their everyday lives [7]. Being sedentary lowers energy expenditure and reduces time for physical activities, leading to weight gain over time.

As overweight young children will more easily become obese and suffer from chronic diseases and psychological problems such as depression or low self-esteem in adulthood [6], a key prevention strategy is to encourage young people to increase their participation in physical activities and exercise. One way this might be achieved is through school-based interventions [8] so that they can make a shift from sedentary behavior and hence reduce the risk of illness [2] [9]. This study draws from this knowledge base to provide young adolescents in one school setting the opportunity to engage in increased activity either informally during school time or outside of school time, using a health engagement model built around the activity of brisk walking.

\section{Brisk Walking}

Brisk walking is a moderate-intensity physical activity that is a safe and simple aerobic exercise. It can be undertaken at any time and place and does not require access to specialist equipment or clothing. There are many benefits of brisk walking, ranging from physical to social and emotional gains. Dunton and Schneider [10] reported that brisk walking $(>3.5 \mathrm{mph}$ ) has been shown to: reduce body fat; lower blood pressure; minimize the risk of fractures; and has also been linked with lower death rates from heart disease and cancer. In terms of engagement, Teerarungsikul [11] importantly revealed that when students developed strong perceptions of self-efficacy and understood the benefits of physical activities, barriers to participation were removed and they liked to participate in the activities and even became interested and active in increasing participation in more physical activities after completion of the program.

Self-efficacy is defined by Bandura [12] [13] as having both the competence and confidence to undertake a task. Bandura's [12] [13] social cognitive theory, which was framed in the context of effective teaching, posited that self-efficacy beliefs are developed from four main sources, namely: 1) enactive mastery experiences (past successes), 2) vicarious experiences (demonstrated by others and making inferences from social comparison), 3) verbal persuasion (encouragement from others to believe in their capabilities) and 4) physiological arousal (resilience). Of these sources, mastery experiences (i.e., performing a task well) is the most effective in increasing sense of efficacy, that is, confidence and competence [14]. Ingvarson, Meiers, and Beavis [15] noted that, where teachers were able to see effective practice modelled and then "try it out", they were more likely to implement new practices or programs. Pendergast, et al. [16] confirmed this to be true in their study of teachers engaging in 
new repertoires of practice. With respect to brisk walking, self-efficacy relates to the techniques and understanding the benefits, hence displaying the competence and confidence to engage in brisk walking and in encouraging others to participate in the activity.

According to Hills \& Byrne [17] and Treuth et al. [18], for brisk walking to be effective for the gains outlined, it is recommended that 30 minutes on each week day or the equivalent of this is required. Whitt, Kumanyika \& Bellamy [19] determined that brisk walking could be carried out in one 30-minute bout or in several 8 - 10 minute episodes. Taking on board this advice, in this study an intervention program has been designed to guide and supervise the participants to engage in brisk walking in two 15-minute episodes for each school-calendarday for four consecutive weeks.

The purpose of this intervention was to encourage participation of junior high school students to proactively engage in regular physical activity. The brisk walking could be conducted in school or out-of-school. The impetus for the program was to encourage physical activity in order to manage body weight at a normal level and increase the level of interest in participation of physical activities. An additional aspiration of the project was to share this experience with others, thereby adding the potential of a ripple effect to achieve greater community awareness of the benefits of brisk walking.

In order to determine the effectiveness of the intervention, four key factors were identified as objective indicators of success, these being that each participant:

1) Spends a minimum 15 minutes taking part in brisk walking on weekdays either in school or at home;

2) Identifies at least two benefits of taking part in brisk walking;

3) Reduces body mass index (BMI) and waist-to-hip ratio (WHR) by 1\%;

4) Introduces brisk walking and its associated benefits to five people.

These four elements will form the reporting framework for the project.

\section{Theoretical Framework of the Intervention Program}

Pender's Health-Promotion Model [20] was utilized in this intervention program to encourage participants to proactively participate in physical activities in school and at home. The model is based on constructs from expectancy-value theory including the Health Belief Model and social cognitive theory, and was selected for its capacity to engage participants in behaviors to enhance their health across life span [21]. Its structure is simple and clear, and allows health educators to plan, develop, implement and assess individual or group health behavioral actions [22]. The three basic components of this model, as presented in Figure 1, are:

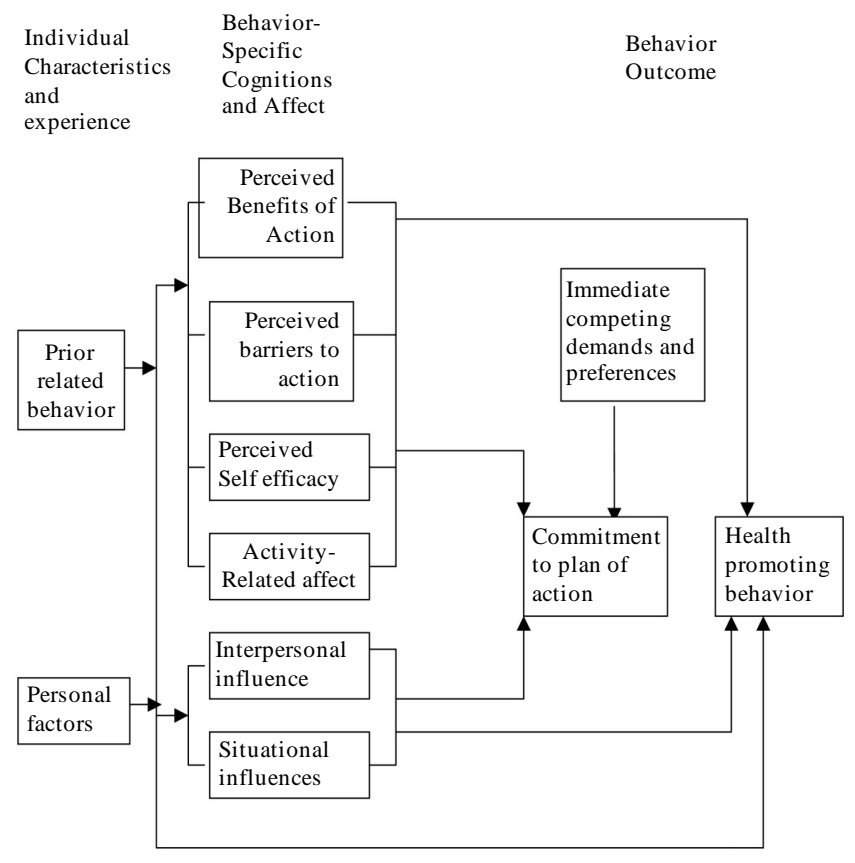

Figure 1. Diagram of Pender's health-promotion model. 
1) Individual characteristics and experiences (e.g. personal, biological, psychological, and social factors, and prior related behavior);

2) Behavior-specific cognitions and affect (e.g. benefits and barriers to action, self-efficacy, interpersonal influences from family, peers, providers and activity-related affect);

3) Commitment to a plan of action and responses to immediate competing preferences.

\section{The Intervention Program Design}

To put the Pender's Health Promotion theory into practice, four activities were designed to facilitate the aims of the project by providing participants with essential knowledge: in relation to the issues of overweight, physical activities and brisk walking; to instill their positive attitudes towards taking physical activities and brisk walking; to develop their fundamental skills to taking physical activities and brisking walking; to cultivate parent influence and support on their interest in taking physical activities and brisk walking; and to enhance and reinforce their decisiveness to continuously take physical activities and brisk walking. The entire intervention program was conducted over a 7-week period, with Activity 1 and 2 held in the first week; Activity 3 conducted over 4 weeks; and Activity 4 held in week seven. Activity 3, Brisk Walking Health Practice, was originally designed to be conducted for at least three months to achieve greater intervention impact as supported by literature, but had to be cut short to one month due to the constraint imposed by the school administration.

Almost two decades ago Resnicow \& Allensworth [23] confirmed that the success of a school health program relies heavily on a well coordinated mechanism. Therefore, a health-promotion committee (hereafter the HP committee) was established in order to: plan and coordinate with the school's environment and resources; collaborate with teachers, students and parents; and, collect and analyze data from evaluations for the training program. To fully understand and be familiar with the techniques of brisk walking, a licensed trainer was engaged to explain and teach the participating school teachers the proper knowledge and exercise of brisk walking. A digitalized video trailer with the trainer and the teachers demonstrating brisk walking was produced to assist in the development of the technique of brisk walking of each participant. The four stages in the intervention are now detailed.

\subsection{Stage 1: Health Talk}

This introductory lecture session provided fundamental knowledge of health education about being overweight or obese to participants by health education academics. It included an educational lecture and videotape, and lasted for one hour. The lecture addressed personal, biological, psychological, and social factors, and prior related behavior in relation to overweight. The following five questions guided the content:

1) What is overweight and obesity?

2) What are the causes of overweight and obesity?

3) What are the health problems due to overweight and obesity?

4) How do you know you are overweight or obese?

5) What should we do to avoid becoming overweight or obese?

\subsection{Stage 2: Health Walk}

This was a second introductory session, in which fundamental knowledge of health education about physical activities and techniques for effective brisk walking was provided. It included a lecture, guest talk and videotape, and lasted for one hour. The lecture component addressed the following content:

1) What is physical activity?

2) What are the benefits of physical activity?

3) What kinds of physical activity suitable and convenient for the students?

4) How long and frequent should we participate in physical activity?

5) What is brisk walking?

6) What are the benefits of brisk walking?

7) When and how can we take part in brisk walking?

During the lecture, the licensed trainer demonstrated the techniques of brisk walking for the participants. A self-explanatory handbook was provided to participants in order to increase their understanding of the benefits of engaging in physical activities and to remove barriers to start doing physical activities by brisk walking. 
After finishing the lecture and demonstration, the students were invited to participate in the 4-week Brisk Walking Health Practice. Those who were interested to participate in the program were required to sign a "Health Behavior Contract" to make a commitment to maintain engagement in physical activity by engaging in 30 minutes of brisk walking every day during the program.

\subsection{Stage 3: Health Practice}

The self-monitored brisk walking was a recurring activity as planned over a four week period. The participating students were self-monitored to undertake brisk walking in two 15-minute episodes at home and they were self-managed to record the date, time and duration of the activity in their personal log sheets, an example of which is provided in Table 1.

When the 4-week Health Practice was completed, the students were requested to submit the personal log sheets to the HP committee and the total minutes taken and total number of days taken within 4 weeks, and average minutes taken a day of brisk walking were recorded.

Based on the total minutes taken during the 4-week brisk walking training, the participants were entitled to a certificate showing that they had completed the program and their level of commitment to the program, ranging from gold, to silver and bronze, which reflected the total minutes committed to the program. In addition, the certificate also stated the level of awards they achieved in accordance with the criteria set in Table 2.

In addition to their participation in the brisk walking program, participants were encouraged to serve as ambassadors for advocating for increasing participation of family, friends and community members. They were also awarded certificates if they achieved these requirements respectively.

\subsection{Stage 4: Health Ambassador}

After the completion of the 4-week brisk-walking, a sharing of the progress of the program from planning to completion was conducted. The event lasted for one hour and participants and their parents were invited to attend an exhibition and ceremony where participation certificates and awards were issued to the participants. In the awards ceremony the singing band "C All Star" as "The Star of the Health Ambassador" of the program were invited to issue the certificates to each of the participating students. At this time participants and their parents were invited to complete an evaluation form with regard to the effectiveness of the program. The content of the evaluation form included participants' satisfaction level and their comments on the activities with suggested improved courses of action.

\section{The Study}

This research was conducted in a government aided school located in North Point in Hong Kong. It is a co-educational school catering students from secondary one to secondary seven. It is a secondary school affiliated to Hong Kong Baptist Church with 30 classes and approximately 1000 students. The school was selected because of the willingness of the school staff to engage in the study and hence forms the unique case study site.

Table 1. Time to be spent (in minute) in each bout of brisk walking session.

\begin{tabular}{ccccc}
\hline Duration & Warm-up time & Brisk-walk time & Cool-down time & Total time \\
\hline Week 1 & 1 & $5-7$ & 1 & $7-9$ \\
Week 2 & 1 & $7-9$ & 1 & $9-11$ \\
Week 3 & 2 & $9-11$ & 2 & $13-15$ \\
Weeks 4 - 9 & 2 & $13-15$ & 2 & $15-17$ \\
\hline
\end{tabular}

Table 2. Criteria for award upon completion of the program.

\begin{tabular}{cccc}
\hline Level & Total min. & Total no. of day & $>16$ \\
Gold & $>480$ & $>420$ & $>14$ \\
Silver & $>360$ & $>12$ \\
\hline
\end{tabular}


Students of two secondary one classes were invited to participate in the program with consent being obtained from students, parents and the relevant school authority. Participants were aged between 12 and 14 years. Seventy-one of eighty students self-selected as participants in this study, following the information session. Of these participants, 33 were males and 38 females. The intervention program was mainly conducted during physical education lessons and the brisk walking component occurred most often after school.

\section{Data Collection}

All participating students completed pre- and post-test data collection for comparative purposes as to the level of involvement and effectiveness of the program. Four data sources were utilized in this study and utilized at pre and post test. These instruments, their administration protocols and purpose, are presented in Table 3.

In addition to these comparative data, a focus group meeting was conducted to solicit participants' views on the design of the intervention program.

\section{Data Analysis}

Data were collected at two times in the program. The pre-intervention data were regarded as the baseline measurement and was collected in Activity 2 "Health Walk" before commencement of Activity 3 "Health Practice", while the post-intervention data were regarded as the post measurement and was collected after completion of the last session of Activity 3 "Health Practice". Descriptive statistics reporting mean and standard deviations of body mass index, waist to hip ration, knowledge about benefits of brisk walking and attitudes towards taking part in brisk walking were calculated using SPSS Version 21. Paired-sample $t$-test was conducted for each pair of pre-post outcome measurements with the level of significance was set at $\mathrm{p}<0.05$.

\section{Findings}

In this program, the 71 participants were junior secondary students in a secondary school recruited to join the brisk walking program. The mean age of the participants was 12 years 6 months $(S D=0.680$; range $=12-15$ ). As presented in Table 4, the mean body mass index of the participants was reduced by $2.75 \%$ when comparing pre and post intervention data. There were significant differences $\left(\mathrm{t}_{(69)}=8.043, \mathrm{p}<0.05\right)$ between the mean body mass index of the participants pre $(20.32 \pm 3.38)$ and post intervention $(19.76 \pm 3.29)$. The mean ratio of the participants was reduced by $6.09 \%$. There were significant difference $\left(\mathrm{t}_{(69)}=2.866, \mathrm{p}<0.05\right)$ between the mean waist to hip ratio of the participants at pre $(0.82 \pm 0.13)$ and post intervention $(0.77 \pm 0.06)$. Regarding the knowledge about benefits of brisk walking, there were significant difference $\left(\mathrm{t}_{(69)}=19.864, \mathrm{p}<0.05\right)$

Table 3. Data collection for pre and post test comparison.

\begin{tabular}{|c|c|c|}
\hline Data collection instrument & Administration & Evidence for indicator of success \\
\hline Body mass index & BMI = Body weight in kilograms/(body height in meters) ${ }^{2}$ & Reduces body mass index (BMI) by 1 \\
\hline Waist to hip ratio & $\begin{array}{l}\text { WHR = Waist measurement }(\mathrm{cm}) / \text { hip measurement }(\mathrm{cm}) \text {; in } \\
\text { which the waist measurement was taken horizontally at the } \\
\text { smaller circumference of the natural waist, just above the belly } \\
\text { button while hip measurement was taken horizontally at the } \\
\text { widest part of the buttocks. }\end{array}$ & $\begin{array}{l}\text { Reduces waist to hip ratio (WHR) by } \\
1 \%\end{array}$ \\
\hline Knowledge questions & $\begin{array}{l}\text { - } 10 \text { structured open-ended questions. } \\
\text { - The numbers of correct answers were scored with one } \\
\text { score given for each correct answer. }\end{array}$ & $\begin{array}{l}\text { Identifies at least two benefits of } \\
\text { taking part in brisk walking }\end{array}$ \\
\hline Attitude questions & $\begin{array}{l}\text { - 5-point Likert Scale was used to measure the participants' } \\
\text { attitude towards taking part in brisk walking by asking the } \\
\text { extent to which they agreed or disagreed with ten } \\
\text { questions. } \\
\text { - Five scales ranging from strongly agree to strongly } \\
\text { disagree for participants to select. } \\
\text { - At analysis stage the five scales were further condensed } \\
\text { and scored accordingly as strongly agree or agree } \\
\text { (value }=3 \text { ), neutral }(\text { value }=2 \text { ), strongly disagree or } \\
\text { disagree }(\text { value }=1 \text { ). }\end{array}$ & $\begin{array}{l}\text { Identifies at least two benefits of } \\
\text { taking part in brisk walking }\end{array}$ \\
\hline
\end{tabular}


Table 4. Results of paired sample t-test of the participant's pre and post intervention.

\begin{tabular}{|c|c|c|c|}
\hline & \multicolumn{3}{|c|}{ Participants $(n=71)$} \\
\hline & Pre & Post & t value \\
\hline Mean height (cm) & $158.69(7.401)$ & $158.94(7.62)$ & $3.641^{*}$ \\
\hline Mean weight (kg) & $51.55(11.54)$ & $50.30(11.39)$ & $7.397^{*}$ \\
\hline Mean waist (cm) & $70.69(10.00)$ & $64.82(8.89)$ & $8.847^{*}$ \\
\hline Mean hip (cm) & $86.93(8.95)$ & $83.77(7.70)$ & $4.368^{*}$ \\
\hline BMI & $20.32(3.38)$ & $19.76(3.29)$ & $8.043^{*}$ \\
\hline WHR & $0.82(0.13)$ & $0.77(0.06)$ & $2.866^{*}$ \\
\hline Knowledge about benefit of brisk walking & $1.51(0.73)$ & $4.59(1.18)$ & $19.864^{*}$ \\
\hline Attitudes towards taking part in brisk walking & $2.11(0.64)$ & $1.94(0.56)$ & $2.682^{*}$ \\
\hline
\end{tabular}

${ }^{*}$ means significant difference at $\mathrm{p}<0.05$.

between the mean score of the participants at pre $(1.51 \pm 0.73)$ and post intervention $(4.59 \pm 1.18)$. For attitudes towards taking part in brisk walking, there were significant difference $\left(\mathrm{t}_{(69)}=2.682, \mathrm{p}<0.05\right)$ between the mean score of the participants at pre $(2.11 \pm 0.64)$ and post intervention $(1.94 \pm 0.56)$.

The findings reveal that $76 \%(n=54)$ of participants achieved the requirements for the respective level of award while approximate $80 \%(n=57)$ of participants spent the desired minimum of 15 minutes to take part in brisk walking in weekdays either in school or at home. Furthermore, a total of 322 names of people were provided by the 71 participants with an average of 4 people recommended through the health ambassador process.

What this data means is that the participating students were able to identify at least two benefits of taking part in brisk walking and reduced BMI and WHR by more than 1\%. Over 75\% of participants would like to spend a minimum of 15 minutes taking part in brisk walking in weekdays either in school or at home, and were interested to introduce brisk walking and its associated benefits to at least four people.

In the focus group meeting, most of the participants reflected that they enjoyed brisk walking very much, revealing a successful design of the intervention program. Their mastery experience of reducing BMI and WHR within a short period of time had undoubtedly enhanced their self-efficacy to combat overweight with brisk walking daily. Brisk walking was identified as one of the useful ways to increase activity level as it could be conducted at anytime, anywhere and free of charge. Receiving awards from " $\mathrm{C}$ All Star" was highlighted as one of the most exciting incentives for their behavioral changes and a role model for observational learning. Peer influence was further identified as one of the effective ways to promote brisk walking.

\section{Discussion}

As stated at the outset, in order to determine the effectiveness of the intervention, four key factors were identified as objective indicators of success, which are being that each participant: spends a minimum 15 minutes taking part in brisk walking on weekdays either in school or at home; identifies at least two benefits of taking part in brisk walking; reduces body mass index (BMI) and waist to hip ratio (WHR) by 1\%; and introduces brisk walking and its associated benefits to five people. After completion of the program, the mean Body Mass Index of the participants was reduced by $2.75 \%$ and the mean Waist to Hip Ratio of the participants was reduced by 6.09\%. With regard to knowledge about benefits of brisk walking and their attitudes towards taking part in brisk walking, the findings reflected that the educational content of the program could help the participating students explore and deepen the knowledge about brisk walking and its associated benefits, and enhance motivation to increase their level of interest in participation of brisk walking. The fourth of these indictors, introducing brisk walking and its associated benefits to 5 people, was not achieved, with instead an average of 4 people being engaged by participants.

From a theoretical perspective, Pender's Health-Promotion Model as illustrated in Figure 1 can be utilized to revisit the success of the program. To put the basic components into this intervention program planning, benefits and barriers to active participation in physical activities were explored in the Health Talk; the licensed dancer-trainer was invited as the guest demonstrator to ensure that participants had effective techniques for brisk 
walking to promote their self-efficacy in the Health Walk; the popular singing band "C All Star" who served as "The Star of the Health Ambassador" provided the participants, in particular, their fans with the observational learning of brisk walking, and participants had to advocate introducing brisk walking and its associated benefits to their family members, peers, schoolmates, neighbor and friends as social support in the Health Practice; certificates showing level of award were issued to the participants by "C All Star" as an incentive for healthy practice; and the participants were required to sign a "Health Behavior Contract" to make a commitment to keeping doing physical activity by accumulated 30-minute brisk walking every day during the program.

With respect to a focus on the development of self-efficacy - that is the confidence and competence to engage in the brisk walking program - the model featured all of the elements promoted by Bandura [12] [13] which notes that self-efficacy beliefs are developed from four main sources: First, the capacity to build by enacting and developing mastery of experiences for the four week duration; second, developing efficacy through vicarious experiences, which occurred through the demonstration of the techniques of brisk walking and acting as ambassadors for others; third, through verbal persuasion by the encouragement from others to believe in their capabilities, including built in incentives; and fourth through the development of physiological arousal, achieved through motivational strategies. According to Bandura [12] of these sources, mastery experiences (i.e., performing a task well) are most effective in increasing a sense of efficacy. This model highlighted this aspect substantially.

The significance of this program is in addressing the elements required for establishing a habit to commit to exercising among the junior secondary students. The example in this case was brisk walking, an easily-adopted exercise to get students moving from their typically sedentary lifestyles. Supported by a role model, this group was interested to commit to the intervention. The results showed the model was innovative and successfully motivated the students. For many exercise programs implemented in association with school settings, one difficulty could be the self-initiative in undertaking the exercise in their leisure time. This study demonstrates a possible solution may be found by engaging simple rewards for those achieving the set target and contributing to a sense of efficacy in undertaking the program. The findings differentiate this intervention program from other intervention programs by considering the role-model effect and the focus upon self-efficacy.

7-week duration of intervention was identified as the major limitation of this study. For a more sustainable development of participants' physical activity habits to combat overweight, it is suggested to increase the duration of intervention and the hours of engaging in physical exercise each day. It is proposed to launch either a single six-month or two sessions of three-month training programs within one school-calendar year and 30 minutes or two sessions of 15-minute training session daily either in the morning session before class or after school. A very supportive school policy and collaborative teaching teams is also a useful recipe for a successful intervention program.

In addition, the participants were self-administrated to take part in brisk walking at home and submitted their self-reported record of personal log sheets. In order to increase the reliability, it is proposed that the participants should be supervised to take part in brisk walking in school and submit their records with endorsement of the supervisor.

\section{What Value Is This Study?}

Overall, the objectives of the intervention program were well attained which demonstrated that the brisk walking program was effective. Sustaining this program would no doubt assist in combatting the challenges associated with young adolescent rates of being overweight or obese, and of attending to the increased patterns of sedentary behavior featured in the contemporary society.

This study is important as it serves as a benchmark for comparison with future data sets in order to investigate the role of interventions and strategies to increase self-efficacy of participants in brisk walking programs, which in turn has the potential to reduce sedentary behaviors and enhance overall health and wellbeing. It is recommended that further studies conducted to investigate the program are a range of settings with regard to the development of sustainable practices.

\section{Acknowledgements}

The authors would like to thank Ms Chen Sik Wing, Law Tak Fai, Leung Yuen Ching and Mak Fung Mei for their contribution to the project. 


\section{References}

[1] Lau, W.C. and Yip, C.Y. (2006) Childhood Obesity in Hong Kong: A Developmental Perspective and Review, 19862005. Journal of Exercise Science and Fitness, 4, 67-84.

[2] Schmid, D. and Leitzmann, M. (2013) Television Viewing and Time Spent Sedentary in Relation to Cancer Risk: A Meta-Analysis. Journal of the National Cancer Institute, 106, 1-19.

[3] Ko, T.C., Ozaki, R., Wong, W.K., Kong, P.S., So, W.Y., Tong, C.Y. and Chan, C.N. (2008) The Problem of Obesity Among Adolescents in Hong Kong: A Comparison Using Various Diagnostic Criteria. BMC Pediatrics, 8, 10. http://dx.doi.org/10.1186/1471-2431-8-10

[4] Chung, L.M.Y., Chung, J.W.Y. and Wong, T.K.S. (2010) Importance of a Balanced Diet on the Physical Fitness Level of School Children Aged 6 - 12. Journal of Child Health Care, 14, 280-295. http://dx.doi.org/10.1177/1367493510374065

[5] Chung, J.W.Y., Chung, L.M.Y., Wong, F.H.T. and Chen, B. (2009) The Impact of Lifestyle on the Physical Fitness of Primary School Children. Journal of Clinical Nursing, 18, 1002-1009. http://dx.doi.org/10.1111/j.1365-2702.2008.02420.x

[6] Cheung, C.H., Ip, L.S., Lam, S.T. and Bibby, H. (2007) A Study on Body Weight Perception and Weight Control Behaviours among Adolescents in Hong Kong. Hong Kong Medical Journal, 13, 16-21.

[7] Brownson, R. and Boechmer, T. (2013) Does the Built Environment Influence Physical Activity? Examining the Evidence. TRB Special Report 282, Paper Prepared for the Transportation Research Board and the Institute of Medicine Committee on Physical Activity Occupation, Transportation, Land Use and Sedentary Behaviours.

[8] Pate, R.R., Davis, M.G., Robinson, T.N., Stone, E.J., McKenzie, T.L. and Young, J.C. (2006) Promoting Physical Activity in Children and Youth: A Leadership Role for Schools: A Scientific Statement from the American Heart Association Council on Nutrition, Physical Activity, and Metabolism (Physical Activity Committee) in Collaboration With the Councils on Cardiovascular Disease in the Young and Cardiovascular Nursing. Circulation, 114, 1214-1224. http://dx.doi.org/10.1161/CIRCULATIONAHA.106.177052

[9] Lee, A., Tsang, K.K., Lee, S.H. and To, C.Y. (2000) A “Healthy Schools” Program in Hong Kong: Enhancing Positive Health Behavior for School Children and Teachers. Education for Health, 13, 399-403. http://dx.doi.org/10.1080/135762800750059516

[10] Dunton, G.F. and Schneider, M. (2006) Perceived Barriers to Walking for Physical Activity. Preventing Chronic Disease, 3. http://www.cdc.gov/pcd/issues/2006/oct/05_0185.htm.

[11] Teerarungsikul, N., Phuphaibul, R., Loveland-Cherry, C.J., Pookboonmee, R., Kijboonchoo, K. and Nityasuddhi, D. (2009) Effectiveness of a Physical Activity Promotion Program on Perceived Self-Efficacy, Physical Activity and Physical Fitness among Thai Adolescent Girls. Thai Journal of Nursing Research, 13, 81-94.

[12] Bandura, A. (1986) Social Foundations of Thought and Action: A Social Cognitive Theory. Prentice-Hall, Englewood Cliffs.

[13] Bandura, A. (1997) Self-Efficacy. Harvard Mental Health Letter, 13, 4-6.

[14] Tschannen-Moran, M. and Hoy, A.W. (2007) The Differential Antecedents of Self-Efficacy Beliefs of Novice and Experienced Teachers. Teaching and Teacher Education, 23, 944-956. http://dx.doi.org/10.1016/j.tate.2006.05.003

[15] Ingvarson, L., Meiers, M. and Beavis, A. (2005) Factors Affecting the Impact of Professional Development Programs on Teachers' Knowledge, Practice, Student Outcomes \& Efficacy. Education Policy Analysis Archives, 13, 1-28.

[16] Pendergast, D., Main, K., Garvis, S. and Kanasa, H. (2013) Teacher Self-Efficacy and Middle Years Teaching: An Insight into a Unique Cohort of Middle Years Educators. Australian Journal of Middle Schooling, 13, 4-19.

[17] Hills, A.P. and Byrne, N.M. (2006) State of the Science: A Focus on Physical Activity. Asia Pacific Journal of Clinical Nutrition, 15, 40-48.

[18] Treuth, M.S., Catellier, D.J., Schmitz, K.H., Pate, R.R., Elder, J.P., McMurray, R.G., Blew, R.M., Yang, S. and Webber, L. (2007) Weekend and Weekday Patterns of Physical Activity in Overweight and Normal-Weight Adolescent Girls. Obesity, 15, 1782-1788. http://dx.doi.org/10.1038/oby.2007.212

[19] Whitt, M., Kumanyika, S. and Bellamy, S. (2003) Amount and Bouts of Physical Activity in a Sample of AfricanAmerican Women. Medicine and Science in Sports and Exercise, 35, 1887-1893. http://dx.doi.org/10.1249/01.MSS.0000093618.60631.C3

[20] Pender, N.J., Murdaugh, C. and Parsons, M.A. (2011) Health Promotion in Nursing Practice. 6th Edition, Pearson, Boston.

[21] Rew, L. (2005) Adolescent Health: A Multidisciplinary Approach to Theory, Research, and Intervention. Sage Publications, Thousand Oaks, London. 
W. W. A. Ma et al.

[22] Guedes, N.G., Moreira, R.P., Cavalcante, T.F., Araujo, T.L.D. and Ximenes, L.B. (2009) Students’ Physical Activity: An Analysis According to Pender's Health Promotion Model. Revista da Escola de Enfermagem da USP, 43, 773-780.

[23] Resnicow, K. and Allensworth, D. (1996) Conducting a Comprehensive School Health Program. Journal of School Health, 66, 59-63. http://dx.doi.org/10.1111/j.1746-1561.1996.tb07910.x 
Scientific Research Publishing (SCIRP) is one of the largest Open Access journal publishers. It is currently publishing more than 200 open access, online, peer-reviewed journals covering a wide range of academic disciplines. SCIRP serves the worldwide academic communities and contributes to the progress and application of science with its publication.

Other selected journals from SCIRP are listed as below. Submit your manuscript to us via either submit@scirp.org or Online Submission Portal.
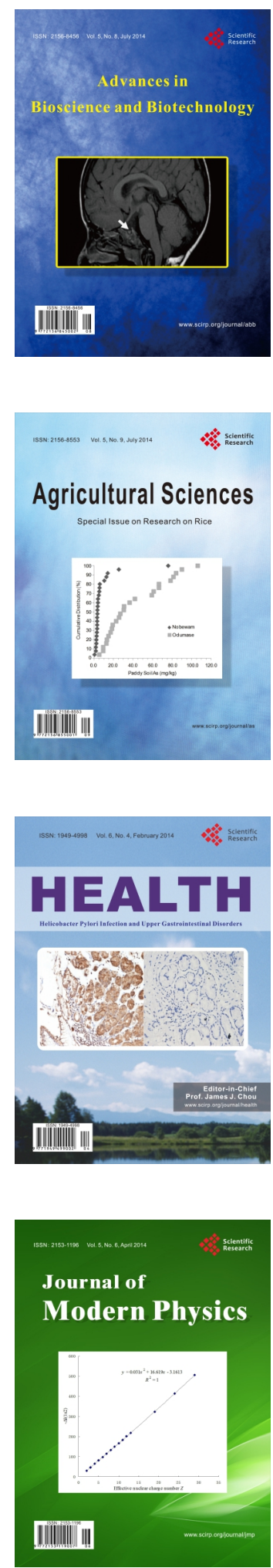
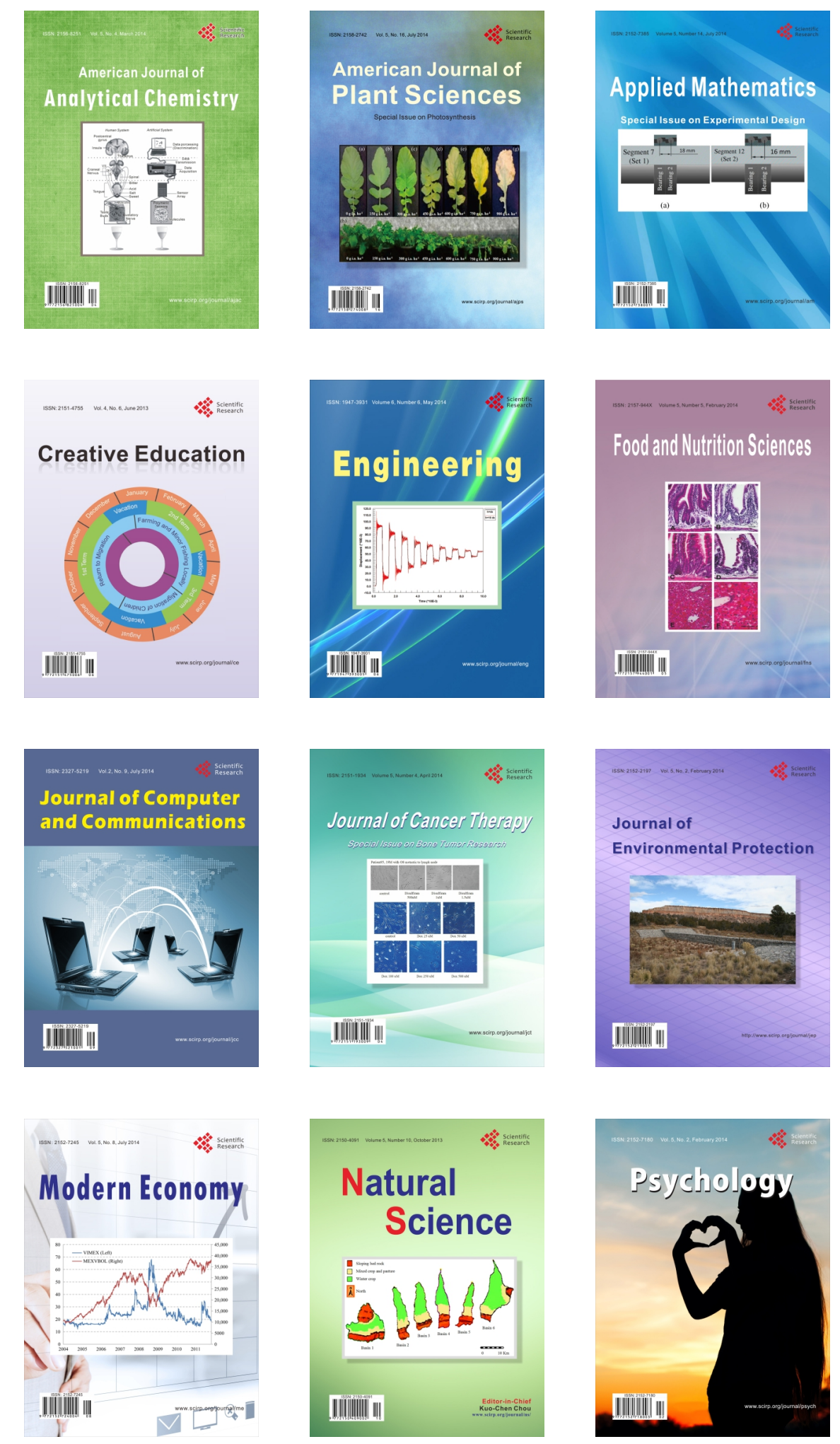